Article

\title{
Emergency Remote Teaching and Learning in Portugal: Preschool to Secondary School Teachers' Perceptions
}

\author{
Filipa Seabra ${ }^{1,2,3, *(\mathbb{D})}$, António Teixeira ${ }^{1,4} \mathbb{D}^{\mathbb{D}}$, Marta Abelha ${ }^{1,5,6} \mathbb{D}^{\mathbb{D}}$ and Luísa Aires ${ }^{1}$ (D) \\ 1 LE@D, Departamento de Educação e Ensino a Distância, Universidade Aberta, 4200-055 Porto, Portugal; \\ antonio.teixeira@uab.pt (A.T.); mabelha@upt.pt (M.A.); Laires@uab.pt (L.A.) \\ 2 CIEd, Universidade do Minho, 4704-553 Braga, Portugal \\ CIPEM/INET-Md, Polytechnic School of Education, 4200-465 Porto, Portugal \\ 4 CFUL, Universidade de Lisboa, 1269-001 Lisbon, Portugal \\ INPP, Departamento de Psicologia e Educação, Universidade Portucalense, 4200-072 Porto, Portugal \\ 6 CEIS20, Universidade de Coimbra, 3000-548 Coimbra, Portugal \\ * Correspondence: filipa.seabra@uab.pt
}

Citation: Seabra, F.; Teixeira, A.; Abelha, M.; Aires, L. Emergency Remote Teaching and Learning in Portugal: Preschool to Secondary School Teachers' Perceptions. Educ Sci. 2021, 11, 349. https://doi.org/ 10.3390/educsci11070349

Academic Editors:

Maria Meletiou-Mavrotheris,

Konstantinos Katzis,

Angelos Sofianidis, Nayia Stylianidou and Panagiota Konstantinou-Katzi

Received: 18 June 2021

Accepted: 9 July 2021

Published: 13 July 2021

Publisher's Note: MDPI stays neutral with regard to jurisdictional claims in published maps and institutional affiliations.

Copyright: (C) 2021 by the authors Licensee MDPI, Basel, Switzerland. This article is an open access article distributed under the terms and conditions of the Creative Commons Attribution (CC BY) license (https:// creativecommons.org/licenses/by/ $4.0 /)$

\begin{abstract}
Emergency remote teaching and learning (ERTL) represent a critical and challenging time for teachers globally. To understand how Portuguese teachers interpreted their ERTL experiences of the first lockdown, we started by asking: What perspectives do teachers have about ERTL? Answering three open questions made available online between April and May of 2020, a sample of 305 preschool, basic, and secondary school teachers expressed their perspectives on (i) difficulties throughout ERTL; (ii) students' constraints in participating in ERTL; (iii) the potential and benefits resulting from this exceptional period. Data were analyzed using content analysis. While Portuguese teachers perceived ERTL with concern, a majority also saw it as an opportunity. Workload, work conditions, and time management were the most frequently mentioned difficulties. Regarding students constraints, teachers emphasized participation, the role of parents, lack of contact, and autonomy. Despite the constraints and difficulties, teachers highlighted gains such as the development of digital competencies and the opportunity to transform teaching and learning. Only 18 teachers suggested there were no positive outcomes from this experience. Since this is an exploratory study, further studies are needed to triangulate the findings.
\end{abstract}

Keywords: emergency remote teaching and learning; COVID-19; teachers' perceptions; child education; primary education; secondary education; distance education

\section{Introduction}

The COVID-19 pandemic swept across the globe, bringing with it unprecedented challenges and impacts concerning not only the physical and mental health of populations [1-4] but also every other aspect of human activity. Education was among the most affected sectors [5-9], as face-to-face educational activities were forced to migrate online due to the closure of schools. In the European Economic Area, up to $90 \%$ of countries promoted schools' closures during the spring of 2020 [10]. As Goodson and Schostack [11] put it, this crisis "appeared like some vast, cruel sociological experiment" (p. 1).

This accelerated digital transition [12] affecting the overwhelming majority of the world's students [5] would become known as emergency remote teaching (ERT) $[13,14]$, emergency remote teaching and learning (ERTL) [15], or emergency remote education (ERE) $[16,17]$. Differently from a quality distance education approach, this educational response to the emergency crisis included moving or replicating activities planned for face-to-face teaching to distance learning environments, without the required conditions, including infrastructure, appropriate methodologies, teacher training, or planning, among others. The use of the expression "distance education" to refer to these practices-which were implemented under very specific conditions, without time for adequate planning 
or teacher training - could therefore contribute to the stigma towards distance education as a lower-quality alternative [14], thus hindering the reputation of distance and online learning [18].

Nevertheless, this transition to ERTL, requiring a very significant effort from governments, local authorities, schools, and teachers, enabled students to maintain some connection to their schools and see their right to education fulfilled, at least in part. As Reimers and Schleicher point out, the utmost priority in this scenario was ensuring the continuity of education, even in the face of challenges and technological constraints [19].

This novel situation has deservedly received attention from many scholars across the globe (for example, $[6,17,20-26]$ ), which is particularly relevant given the fact that the pandemic did not impact every country in the same ways or at the same time, and there were different approaches to how governments dealt with the situation, as well as different social economic and cultural conditions, giving rise to context specificities that should be recognized and addressed by educational research. While some studies or theoretical reflections from the Portuguese context have been published [12,27-34], a qualitative study into teachers' perspectives on ERTL, focusing on their initial responses to the first lockdown and teachers from preschool to secondary education, has still not been published. This highlights the relevance of the present study, which aims to present the perspectives of 305 Portuguese preschool (students aged 3-6), 1st, 2nd, and 3rd cycles of basic education (CBE) (students aged 6-14), and secondary education (students aged 14-18) about their difficulties with the transition to ERTL, and their students' constraints, but also the potential and positive aspects they recognized in the process.

\subsection{Stages of ERTL in Portuguese Preschools to Secondary Education}

The educational responses to COVID-19 have been described as having four phases [14,35], including:

Phase 1: Rapid transition to remote teaching and learning corresponded to the first effort by institutions to ensure that activities planned for face-to-face teaching would be transferred online over the course of four weeks. Authors have described this phase as having a predominance of synchronous video communication $[14,35]$, a phenomenon that has been referred to as "zoomism" [26,28]. This phase was characterized by the concern with making sure students had some access to education without the time to consider the details.

Phase 2: (Re)adding basics gave rise to a (re)emergence of concerns with quality, such as course design, equity and accessibility, or academic integrity in terms of the ERTL practices that were already in place $[14,35]$.

These two stages correspond to ERTL and would be followed by more advanced stages of what is referred to as remote teaching. Primary conditions for quality were then established, as institutions and teachers could build on their initial experience. However, we will not go into those phases more deeply because our data gathering occurred during phase 2. Instead, we will proceed to describe how these two phases, initially described for higher education [35] and later adapted to k-12 education [14] in the Canadian context, can be used as a framework for understanding what was happening in Portuguese preschool to secondary education.

\subsection{Stages of ERTL in Portuguese Preschool to Secondary Education}

Like many other countries in the world, the Portuguese government ordered the physical closing of all schools starting on 16 March 2020, as a measure to mitigate the propagation of the COVID-19 pandemic. The exceptional circumstances brought about by the pandemic put the Portuguese educational system to the test, requiring educational processes devised to be held face-to-face to be transposed into ERTL. This enabled Portuguese students to carry on with their educational processes, despite being confined to their domiciles. Due to this new reality, and to help students, teachers, and families, the Ministry of Education issued a set of recommendations and support measures. 
As an answer to the solicitations of schools at the beginning of the pandemic crisis, the Ministry of Education created a website called "Support to Schools", where information is made available to all students, teachers, directors, parents, and other stakeholders. A growing set of materials and resources has been presented as support to teaching and school management to enrich and add value to the learning and teaching processes during the pandemic. This initiative has been effective in addressing access to documents, information, and national and international guidelines, invaluable to the construction of adequate responses to the current global problems.

On 27 March 2020 (10 days after the schools' closure), the General Directorate of Education issued a document under the title "Guiding principles for the implementation of Distance Education at Schools" [36], which presented suggestions and recommendations for the development of "distance learning". With this document as a guideline, schools were asked to develop their distance teaching plans, considering their contexts and realities. This has led to the emergence of communities of teachers at the school level that would have an important role in the regulation of the process.

Later, on 15 April 2020, and resulting from a partnership between the Ministry of Education and the Universidade Aberta (Open University, Portugal) — the only public distance higher education institution in Portugal-a teacher training course was launched [37]. This course was developed by over 2300 teachers from basic and secondary education and was intended to promote a space for reflection on the pedagogical changes necessary for the transition and adaptation to distance education and on the potentials offered by technology allowing teachers to move beyond an emergency pedagogical response [30].

Approximately one month after the schools' closing (20 April 2020), the television program "Study at Home" was launched, allowing even the most isolated students to access relevant educational content, regardless of difficulties in accessing a computer and broadband internet. Other measures aimed at balancing the concerns about equity [26,38] with matters of academic integrity [35] were: (i) the suspension of all national exams for basic education (2nd, 5th, 8th, and 9th grades) and (ii) the suspension of all teaching activity during the third term (14 April to 26 June) except for older students (11th and 12th grades), who returned to face-to-face school on 18 May 2020 but only for the subjects for which they would be required to perform a national exam in order to apply to higher education.

As Flores and Gago [33] noted, one of the primary and most complex challenges imposed by the pandemic on educational systems worldwide was the inequality in access to electronic devices and to the internet, which prevented some students from accessing adequate ERTL. Portugal was no exception, and to respond to that challenge, local institutions and authorities provided students in need with resources-such as computers and internet hotspots-allowing them to access ERTL and lessening the social inequalities that were reflected in school inequalities that compromise the objective of quality education for all. The role played by local institutions in the educational response was particularly relevant in developing countries [39] but cannot be underplayed even in a European country such as Portugal.

Even though the reaction to the pandemic was swift [40], the otherwise very centralized educational system responded by adopting decentralized policies that relied on schools' capacity for decision making and self-organization and were meant to promote contextual adaptation. Still, this attitude may have led to discoordination and inequality, even if many schools rose to the challenge with creativity and innovation.

\subsection{Teachers' Perceptions and Challenges in the Face of ERTL}

A variety of challenges have been attributed to ERTL, namely at the technological, pedagogical, and social levels. Technological challenges relate to the quality and availability of internet connections and students' access to the necessary hardware. Pedagogical challenges include teachers' and students' limited digital competences, teachers' inability to manage online resources and design digital learning environments, a lack of interaction and motivation, and teachers' difficulty in ensuring social and cognitive presence. Finally, 
social challenges include the lack of interaction among students or between students and teachers, the physical conditions for learning at home, and parents' availability and support [41].

In a Canadian qualitative study, K-12 teachers have noted several challenges associated with the transition to ERTL [42], organized around six emerging themes: change, vulnerability, transitions, work/homelife balance, holistic teaching responses, and communication.

Change in work rhythms and the workload was noted, although not always in a negative light, as some teachers experienced this as a time for growth. Working "nonstop" was mentioned by a teacher who was also a mother and had supervision responsibilities. Teachers reported working very hard to develop engaging activities for their students, which sometimes caused tension with families and their expectations. Using synchronous communication tools also proved challenging [42]. In terms of vulnerability, teachers worried about their students, particularly those with learning differences and in isolation. Parents would sometimes be overinvolved in schoolwork. Differences were reported, as some students improved their attendance, while others struggled and required more face-to-face interaction [42]. The theme of transitions concerned the preoccupation with what school would look like in September with the return to a "new normal". Teachers expressed concerns about induction year students and finalists, who might lack closure or have more difficulty with transitioning into a new cycle. Work/home life balance emerged as the most vigorous reaction among participants in this study. For teachers who were parents themselves, this was described as a "juggling act" (p. 11). Concerns about returning to school, specifically health issues and the struggle of young children keeping social distancing, were voiced by elementary and middle school teachers. Teachers also worried about how they would be able to comfort and support students without physical touch. Social and economic concerns regarding students' families were also voiced, and teachers assumed a role in caring for families in distress. Communication was problematic as teachers felt confused about the expectations placed upon them. Communication with parents was also a source of concern, especially when contact attempts were not answered.

Another Canadian study of teachers' attitudes [43] in the early stages of the pandemic revealed: (i) teachers' positive attitudes towards change, positive perceptions of principal support, teaching efficacy, and positive attitudes towards technology correlated positively with one another and with teacher resilience, and negatively with teacher burnout (p. 5); (ii) there were significant changes in teachers' attitudes from April to June 2020, as efficacy for behavior increased, but burnout also increased and affective and cognitive attitudes towards change became less optimistic.

A Spanish study [23] stressed the role of teachers' digital competences, seen as one of the main constraints to ERTL. The study found a gender and age divide in teachers' levels of competence, as well as lower levels of digital competence among teachers of younger children. Teachers with lower digital competence perceived a higher workload and more negative emotions towards ERTL.

Reinforcing and upgrading the level of digital competence of all educational actors is therefore of critical importance. This includes digital pedagogy for teachers and raising awareness about cybersecurity and data ethics [44]. These findings should lead to changes in educational policy, particularly in factors related to teacher training. However, they should also inspire a refocus of the research agenda on digital competence, as suggested by a panel of international experts [16].

Childhood education teachers were faced with specific challenges, given the characteristics of their students. Studies of previous crises have highlighted the long-term consequences they have caused for children's learning and development [45]. As childhood education is geared towards providing children with "real-life sensory experiences, hands-on activities, and meaningful face-to-face interactions" (p. 3), it is particularly challenging to move online. Spitery [45] also cautions readers about the inequalities that can be heightened in this situation due to differences in parental support and conditions, and the distance from other children and caring adults. These economic and even psychological 
conditions may also have become more inequitable due to the pandemic. Teachers also expressed concern about kindergarten children's socialization [42].

In the USA, teachers expressed needing support to find strategies directed at keeping students engaged and motivated, addressing the lack of hands-on learning (such as internships or labs), assessing students' social and emotional wellbeing, assuring psychological and counseling support to students, social and emotional lesson plans, assessing student learning, technical support, and adapting the curriculum to the current circumstances, among other less frequent concerns [22].

The experience of teachers of special education students is also particularly relevant in the context of ERTL, as matters of equity and inclusion are particularly salient in the context of this crisis $[30,42,46]$. In this context, three stages have been defined: (i) making contact, (ii) establishing routines, and (iii) transitioning to academics. Authors have also reported challenges, such as the inequity of resources and parental support, the difficulties inherent to teaching through digital mediation, experiencing tensions between the accountability they knew their students needed and their motivation and attendance, and coping with the shifts in their own professional lives, such as the amount of time spent on online meetings or the worry about "doing enough" [46].

Matters of equity, not only concerning children with special needs but also socially disadvantaged children, have been highlighted by this experience, as moving learning online seems to disproportionately and negatively affect those from disadvantaged communities. The lived experiences of diverse students, teachers, and families were also particularly upheaved by this crisis [38]. Providing equitable education to all students was the most relevant concern expressed by school principals in a study based in the USA [22]

This experience has, nonetheless, been pointed out as an opportunity for rethinking curricula, teaching, learning, assessment, and educational organization and management $[9,27,31,45,47]$. Moreover, the development of social and emotional competences, which is especially relevant for students, in particular self-regulation, social skills, and selfcare, was noted as having improved during the crisis [44] Stressing cooperative and mutual learning and fundamentally changing the teacher-student roles is seen as a possibility, and therefore returning to "normal" can be feared more than desired [11].

\section{Materials and Methods}

Data were gathered by questionnaire between 24 April 2020 and 19 May 2020. The lockdown of schools was decided on 13 March 2020. Data gathering began only six weeks into this process, and completed shortly after two months of lockdown, therefore capturing a short window portraying initial educational responses to the pandemic and the experiences associated with them.

The questionnaire was previously validated by the ethics committee of the research center, which hosts the research, and the ethical guidelines for educational research were carefully observed throughout the process [48].

The specific data presented in this article concern three open-ended questions intended to capture teachers' perceptions on (i) their difficulties throughout the process, (ii) their students' constraints in adapting to the process, and (iii) the potentials and benefits emerging from the situation.

A total of 305 teachers of all nonhigher education levels answered at least one of the open questions, producing unstructured responses of varying degrees of development, ranging from a few words to several paragraphs. This is a convenience sample, as teachers individually decided to participate in the study - the questionnaire was disseminated through social media, particularly in forums dedicated to education.

The resulting data were analyzed using MaxQda software $[49,50]$ with an entirely deductive approach, to develop a thematic categorization and subsequent thematic content analysis. Emerging categories were refined and organized into higher-level categories, whenever relevant, in order to aid in the identification of the most relevant themes being addressed by participants and help convey organization and structure in the data presenta- 
tion. Due to the large number of answers, we chose to quantify answers, thus conveying the prevalence of themes across multiple answers. Nevertheless, we are rooted in a qualitative, interpretative approach when analyzing data and, therefore, we also frequently present respondents' words verbatim to better illustrate the positions they expressed [49,51-53].

Participants represented all of Portugal's regions and presented a diverse profile, as is expressed by Tables 1 and 2 .

Table 1. Respondents' and their schools' characteristics.

\begin{tabular}{cccc}
\hline & & Frequency & Valid Percent \\
\hline \multirow{2}{*}{ Gender (305) } & Feminine & 244 & $80 \%$ \\
& Masculine & 61 & $20 \%$ \\
\hline \multirow{3}{*}{ Age (305) } & 25 or under & 2 & $0.7 \%$ \\
& $26-35$ & 7 & $2.3 \%$ \\
& $36-45$ & 95 & $31.3 \%$ \\
& $46-55$ & 119 & $39.1 \%$ \\
& $56+$ & 81 & $26.6 \%$ \\
\hline \multirow{3}{*}{ Academic training (302) } & Bachelor's & 6 & $2.0 \%$ \\
& Undergraduate & 189 & $62.6 \%$ \\
& Master's & 92 & $30.5 \%$ \\
Social economic status of & Doctorate & 15 & $5.0 \%$ \\
\hline population taught (303) & Mostly in need & 33 & $10.9 \%$ \\
& Mostly lower average & 208 & $68.6 \%$ \\
& Mostly higher average & 62 & $20.5 \%$ \\
\hline \multirow{2}{*}{ Type of school (305) } & Public & 270 & $88.5 \%$ \\
& Private & 34 & $11.1 \%$ \\
\hline \multirow{2}{*}{ School context (305) } & Rural & 38 & $12.5 \%$ \\
& Urban & 134 & $43.9 \%$ \\
& Semi-urban & 74 & $2.3 \%$ \\
& Hybrid & 59 & $19.3 \%$ \\
\hline
\end{tabular}

Table 2. Levels and subjects taught.

\begin{tabular}{cccc}
\hline & & Frequency & Valid Percent \\
\hline Level taught & Preschool & 35 & $11.5 \%$ \\
& 1st cycle of basic education (CBE) & 54 & $17.7 \%$ \\
& 2nd CBE & 41 & $13.4 \%$ \\
& 3rd CBE & 57 & $18.7 \%$ \\
2nd and 3rd CBE & 10 & $3.3 \%$ \\
& 3rd CBE and secondary & 38 & $12.5 \%$ \\
Subjects taught (303) & Secondary & 55 & $18.0 \%$ \\
& Other combination & 15 & $4.9 \%$ \\
\hline & All subjects (preschool and 1st CBE) & 76 & $25.1 \%$ \\
& Languages & 70 & $23.1 \%$ \\
& Natural sciences and math & 65 & 21.5 \\
& Social sciences and humanities & 25 & $8.3 \%$ \\
Special education and support & 20 & $6.6 \%$ \\
& Arts and expressions & 18 & $5.9 \%$ \\
& Physical education & 12 & $4.0 \%$ \\
& Technical subjects & 11 & $3.6 \%$ \\
& Other/combination & 6 & $1.9 \%$ \\
\hline
\end{tabular}

\section{Presentation and Discussion of Results}

We will present an overview of teachers' perceptions concerning the three main categories in our study: (i) teachers' difficulties, (ii) students' constraints (as perceived by teachers), and (iii) potential and positive aspects. 


\subsection{Teachers' Difficulties}

A total of 294 teachers answered the open question, "Please identify the main difficulties you have felt in this process of accelerated transition to distance teaching, as a teacher".

Their responses, ranging from a few words to several paragraphs, expressed several concerns, which we organized into three main categories-work (163 references by 118 respondents), conditions (177 references by 133 respondents), and time management (134 references by 110 respondents) — each of which was specified by several lower-level categories, and four complementary categories-students (139 references by 111 respondents), no difficulties (4), impossibility (3), and consequences (14). The frequency of references and respondents represented in each category, as well as the valid percentage (of respondents), are displayed in Figure 1.

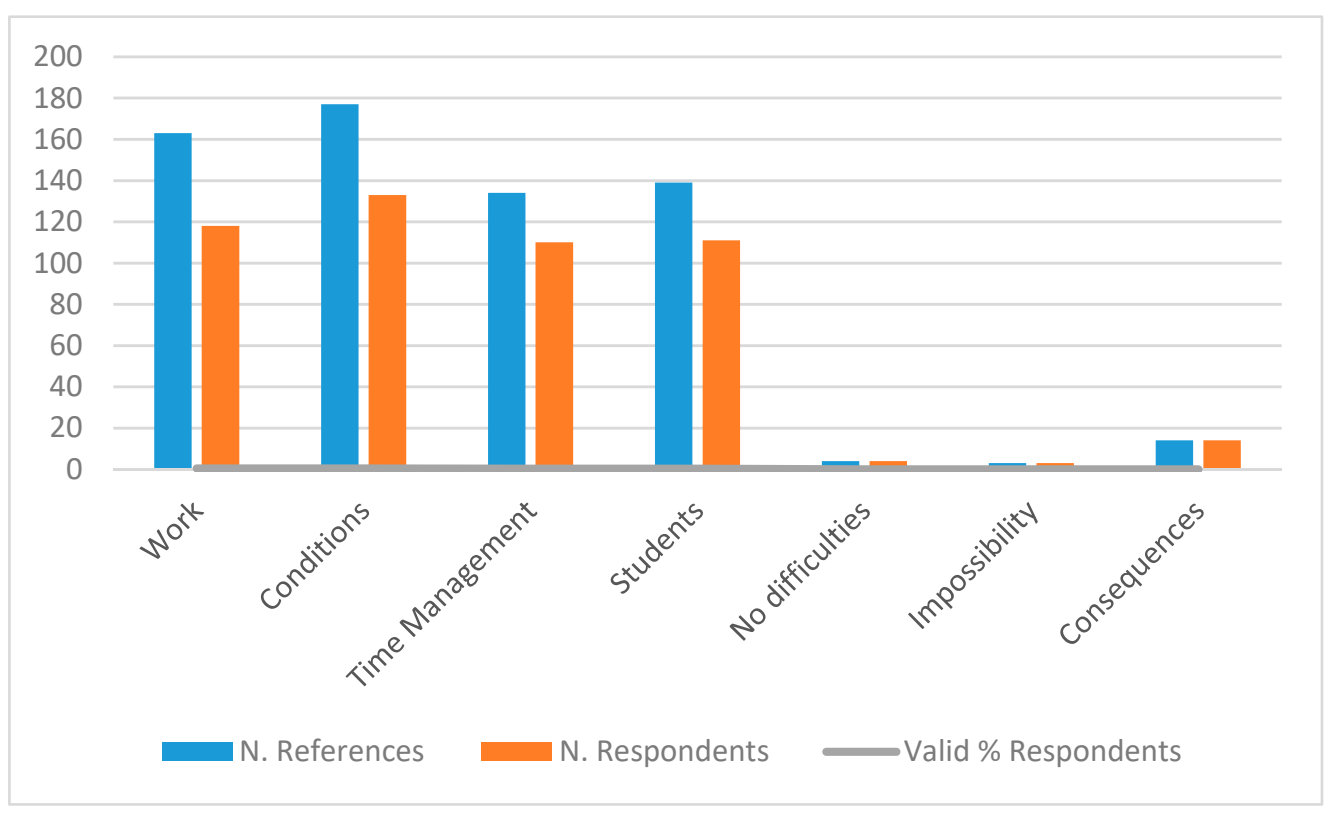

Figure 1. Teachers' difficulties: an overview of responses and respondents to each category.

\subsubsection{Work}

Within the category pertaining to work (163 references), we included nine categories: overload (37), changing strategies and activities (35), (un)coordination (30), evaluation and feedback (29), adaptation (10), colleague support and relations (9), rush/lack of reflection (8), limited learning (4), and laboratory practices (1) (frequency and valid percentage of each subcategory are presented in Figure 2).

The reference to an excess of work-related tasks was one of the most prevalent complaints among teachers, such as respondent (from now on abbreviated to r. 37) "the COVID phenomenon represented a significant increase of my workload" or r. 47 "The number of hours of direct work with students has more than doubled". This related to the next category, concerning having to alter what was planned and adapt activities and materials; in the words of $r .198$ "preparing materials for this kind of teaching takes quite a bit longer" or r. 209 "Much of the work I had prepared pre-Covid19 was thrown into the trash. So, I had to plan again".

The perception of work overload correlated with teachers' lack of digital competence in the work of Portillo and colleagues [23]. The workload, and its balance with homelife demands, also emerged in MacDonald and Hill's study [42]. 


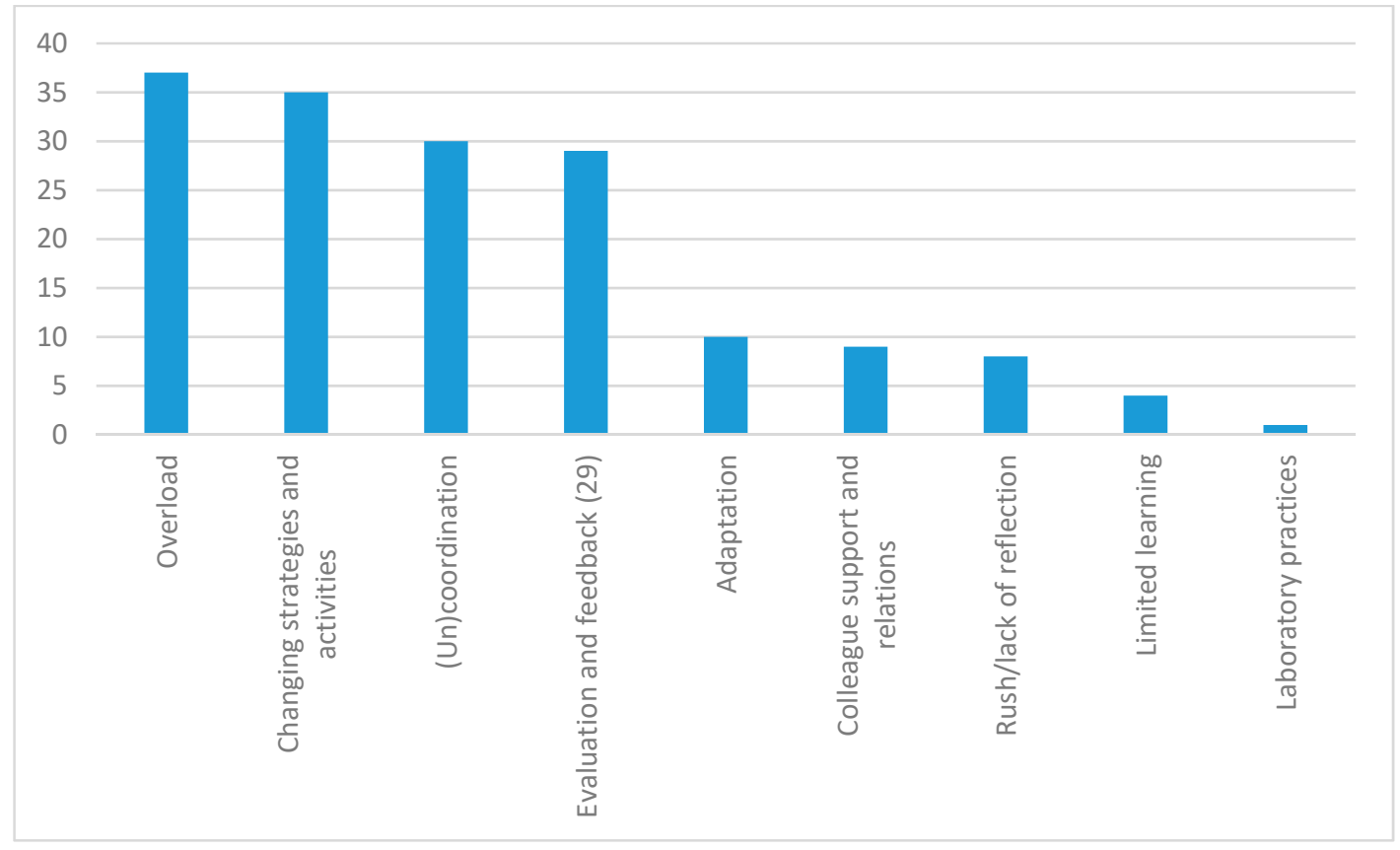

Figure 2. Teachers' difficulties: frequency of references to subcategories, under the category of work.

The burden of work is not helped by the fact that many teachers felt coordination was missing, insufficient, or inefficient at several levels, ranging from the Ministry of Education,

"the Ministry threw the hot potato at schools and teachers" (r. 209),

"the absence of clear and defined rules on what contents are intended to be taught" (r. 26),

to the school or department levels,

"receiving new guidelines everyday" (r. 35),

"the directives that should guide my work appeared after solutions were already adopted, in order to avoid abandoning the students from the first moment. Once procedures were adopted, which were different from class to class, it is hard to demand people to adapt to new procedures" (r. 96).

These concerns and lack of clarity of guidelines were also expressed by teachers in MacDonald and Hill's study and were organized under the category of communication [42]. These findings disagree with a more positive view of how central policy guided teachers' work in Portugal [30].

Specific concerns about evaluation, assessment, and feedback were also present in some of the answers, many of which highlighted the amount of time required to give every student feedback on the activities they were developing, while others questioned the possibility of evaluating students' learning, raising the issue of authenticity. For instance:

"Having to answer over 140 students every week, filling out work plan tables, and balance sheets weekly for six classes, four of which with two subjects" (r. 166),

"tasks produced by the parents, not the students" (r. 185),

"If we were to take it seriously, we should long have assumed it is impossible to make a fair evaluation [of students learning]" (r. 209).

Concerns with evaluation were a defining characteristic of phase 2 of ERTL [14,35] and were also expressed by teachers in another study [22].

Although less frequently, teachers referred to needing to adapt to a new reality, being constantly required to give support to their colleagues, or encountering difficulties due to some colleagues not being open to change and reported having to implement changes 
without time for reflection-aspects that relate to the category of change [42]. A few teachers considered that the methods adopted did not allow learning to take place, and one was concerned about laboratory practices. A concern with practical learning activities was also expressed by teachers in the USA [22].

\subsubsection{Conditions}

In the category pertaining to conditions, subcategories emerged pertaining to platforms and tools (64), equipment (31), the internet (25), digital competences (23), training (23), a lack of knowledge about distance learning (6), data protection (3), and the number of students per class (2) (Figure 3).

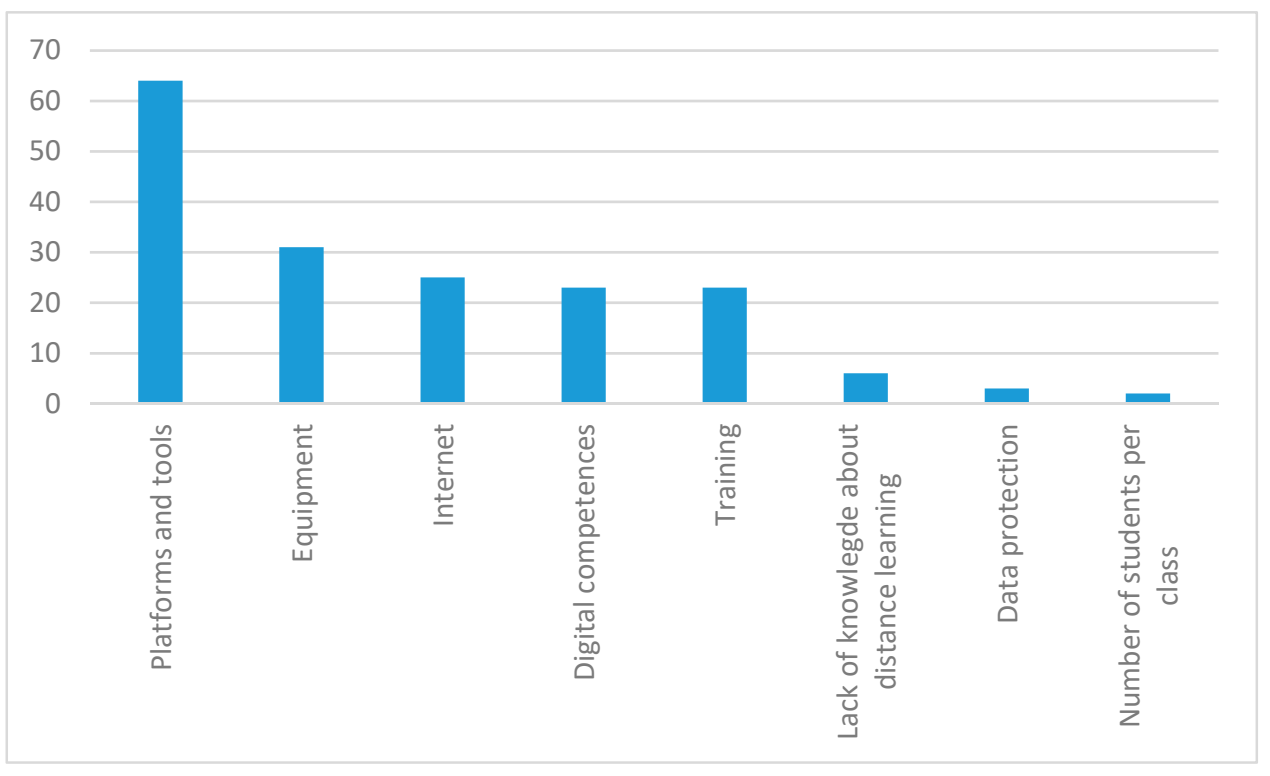

Figure 3. Teachers' difficulties: frequency of references to subcategories, under the category of conditions.

Many teachers (64) voiced concern about learning or adapting to the use of specific platforms or technologies. A pervasive concern about learning how to maneuver technology was, therefore, evident. For instance:

"Quickly needing to become familiar with synchronous and asynchronous platforms, time to explore applications" (r. 8),

"Not being trained on the platform chosen by my school cluster" (r. 26).

Next, concerns about the availability of technological equipment (31) and a reliable connection to the internet (25) were expressed. Many of these referred to their students' access to computers and to the internet, such as: "some students don't have a computer, and the smartphone is inadequate for some tasks" (r. 16), sometimes considering the inequities caused by the different levels of access to technology among students, which will be highlighted in another topic. Nevertheless, teachers' access to equipment and the internet were also mentioned by some respondents:

"My informatics equipment is obsolete, it keeps blocking and is extremely slow, which is driving me to desperation ... and my internet access was insufficient, so I had to purchase another access card" (r. 268).

When considering the lack of digital competencies, teachers also directed their concern both towards themselves and towards their students, which sometimes extended to their parents:

"I feel insecure and have difficulty working with ICT" (r. 68),

"Making information reach everyone, because of the parents', and students'

difficulties when using programs and digital platforms" (r. 101). 
Interrelated with this concern is the need many teachers expressed for training, or the complaint about having to do everything at once: training/self-training, adapting to a new teaching method, and accompanying students, which added to the workload-related aspect mentioned before. One teacher vented, "Training is all very nice, but reality only happens in practice" (r. 239). More seldomly, teachers expressed worry about not knowing enough about distance learning, about data protection, and about the number of students with whom they work, hindering a more personalized approach.

Technological concerns were one of the areas identified in the study by Ferri and collaborators [41], as were teachers' digital competencies, included as one of the pedagogical challenges; teachers' digital competences correlated negatively with how they perceived their workload - which we previously established was a primary concern for the teachers in our study-and negative emotions towards ERTL [23]; another study revealed that teachers' attitudes towards technology negatively correlated to their levels of burnout [43]. All these results highlight the pertinence of investing in teacher training in digital competences, as is highlighted by UNESCO [54].

\subsubsection{Time Management}

Time was a pervasive theme throughout the answers to this question, so much so that it seeps through to all the other categories to some extent. Within the category of time management are three closely interrelated subcategories: time (93), personal/family life (33), and students' time (8) (Figure 4).

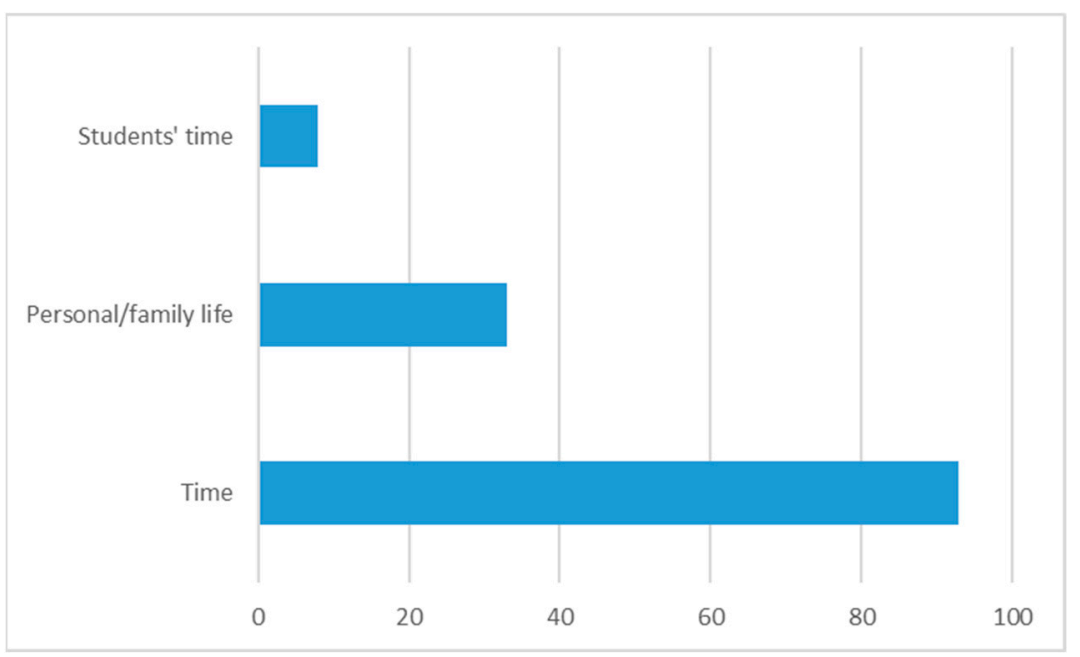

Figure 4. Teachers' difficulties: frequency of references to subcategories, under the category of time management.

The concern about time- - not having enough time for everything, being constantly pressed for immediate answers-was the most prevalent of all the concerns expressed by the respondents (91 out of the 249 respondents expressed this concern 93 times). Expressions like "rapid" (8), "short deadlines" (12), "urgency" (15), or "lack of time" (24) are spread throughout the answers and color the whole sentiment expressed by the teachers.

Closely connected to this idea is the concern about personal and family life boundaries becoming diffused or being actively disrespected, and the difficulty of juggling all the different roles. For instance:

"Taking into account we are at home with our family, and there is a whole family logistics, it becomes inhumane" (r. 12);

"Not having time for my own family. I stopped having a work schedule and family time, because I am constantly getting calls and messages from the school, from parents, from colleagues, at any hour of the day and even the night" (r. 88); 
"Conciliating work with the fact that I have two very small children whom I have to take care of alone" (r. 97);

"Difficulty managing time, clearly separating 'being at school' and 'being at home'" (136).

The concern with balancing work and family life was one of the categories considered in MacDonald and Hill's study [42], particularly for teachers who were also parents.

Lastly, a small number of teachers also showed concern about students' time management, with eight teachers referring to students' excessive workload.

\subsubsection{Students}

It is interesting that even though the question clearly stated we were interested in the difficulties experienced by the teachers themselves, respondents frequently could not separate their personal worries from the worries they feel for their students. Not only were there concerns about students interspersed in the aforementioned categories (students' access to computers and the internet, their digital competence, their workload), but there was also an emergent category related to students, comprising the following subcategories: student participation/motivation (42); parents (41); equity (29); lack of contact (18); and autonomy (9) (Figure 5).

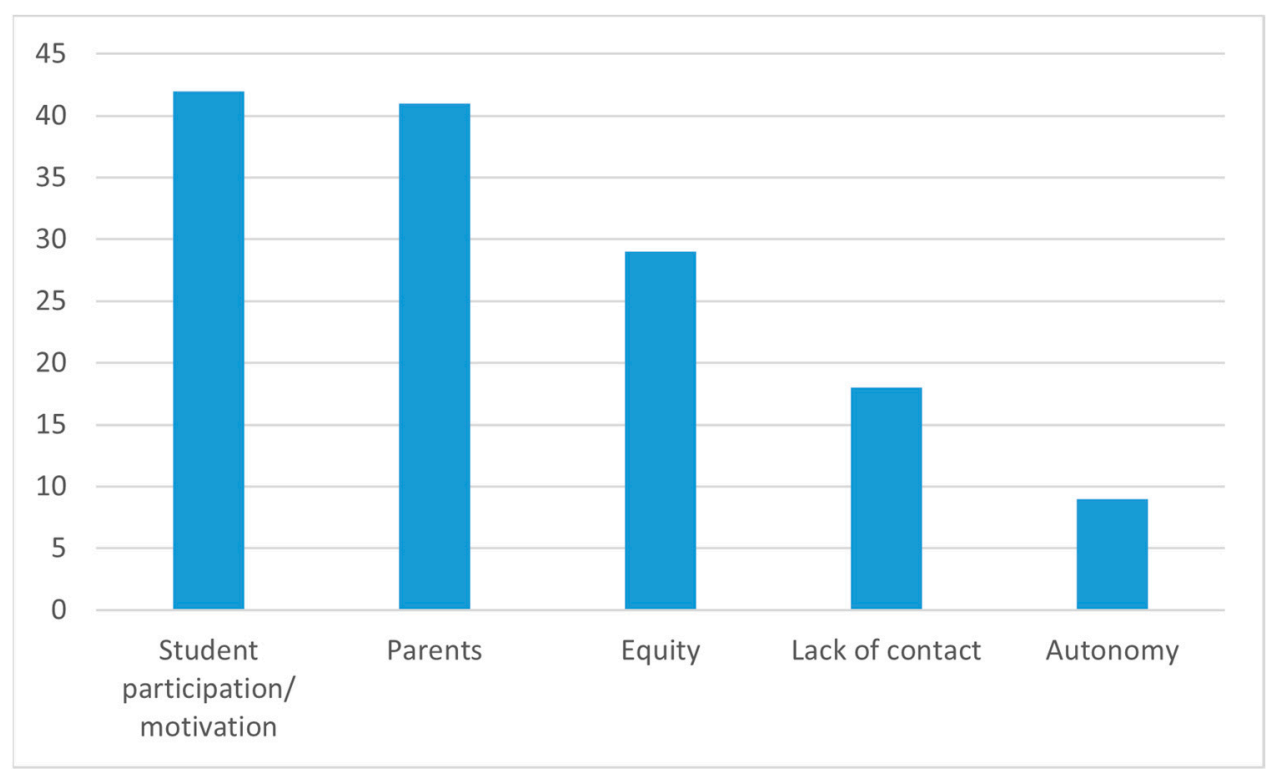

Figure 5. Teachers' difficulties: frequency of references to subcategories, under the category of time management.

We will not analyze all these subcategories in detail, given there was another question specifically directed to students' limitations, where these same concerns also emerge.

\subsubsection{No Difficulties/Impossibility}

On opposite ends of the spectrum are the few teachers who expressed no experience of difficulties (4) or finding distance teaching impossible (3). Although these extreme positions were rare, we considered the possibility they might be significant and therefore investigated other characteristics of these respondents that might help to identify a trend. Our attempt was not fruitful. We might expect younger teachers, ICT teachers, and teachers of older students to be among the "no difficulties" group. However, these four teachers ranged in ages from 36 to 56 and over, included a preschool teacher and teachers of older students, and included an ICT teacher, but also one math teacher and one physical education teacher. On the other end of the spectrum, the teachers who saw this endeavor as impossible ranged 
in age from 26 to 55 and included one preschool teacher, and one teacher of the 1st cycle of basic education, but also a history teacher who taught older students.

\subsubsection{Consequences}

Lastly, 16 respondents expressed concerns about the consequences of this experience, ranging from physical complaints (headaches and backaches due to long periods of sitting in front of screens) to mental wellbeing consequences (fatigue, exhaustion, anxiety, fear, insecurity). Although our work does not center on health or mental health concerns, these emerged naturally from the respondents' answers and are noteworthy, even though the data were gathered shortly after confinement. We might expect that later into the confinement, these aspects might become more prevalent, and we believe they deserve further attention.

Sokal and colleagues [43] found increasing levels of burnout from April to June 2020. Mental health concerns $[1,2]$ related to the pandemic were also reported in other populations.

\subsection{Students' Constraints}

Considering that the present paper focuses solely on teachers' perceptions, it is important to note that the points presented in this category are not students' self-reported constraints, but rather reflect teachers' perceptions of the constraints affecting their students.

Two hundred ninety-one teachers answered the question, "Please, identify what have been, in your perspective, the main constraints on the part of students/children for adapting to this process of accelerated transition to distance teaching".

Their answers were organized into three main categories-conditions (451 references by 246 respondents), time management ( 76 references by 61 teachers), and relationships (52 references by 39 respondents) —each of which was subdivided into subcategories and three complementary categories-well adjusted (18), impossible (2), and inequity (10) (Figure 6). We also considered the answers to the previous question when categorizing concerns with students.

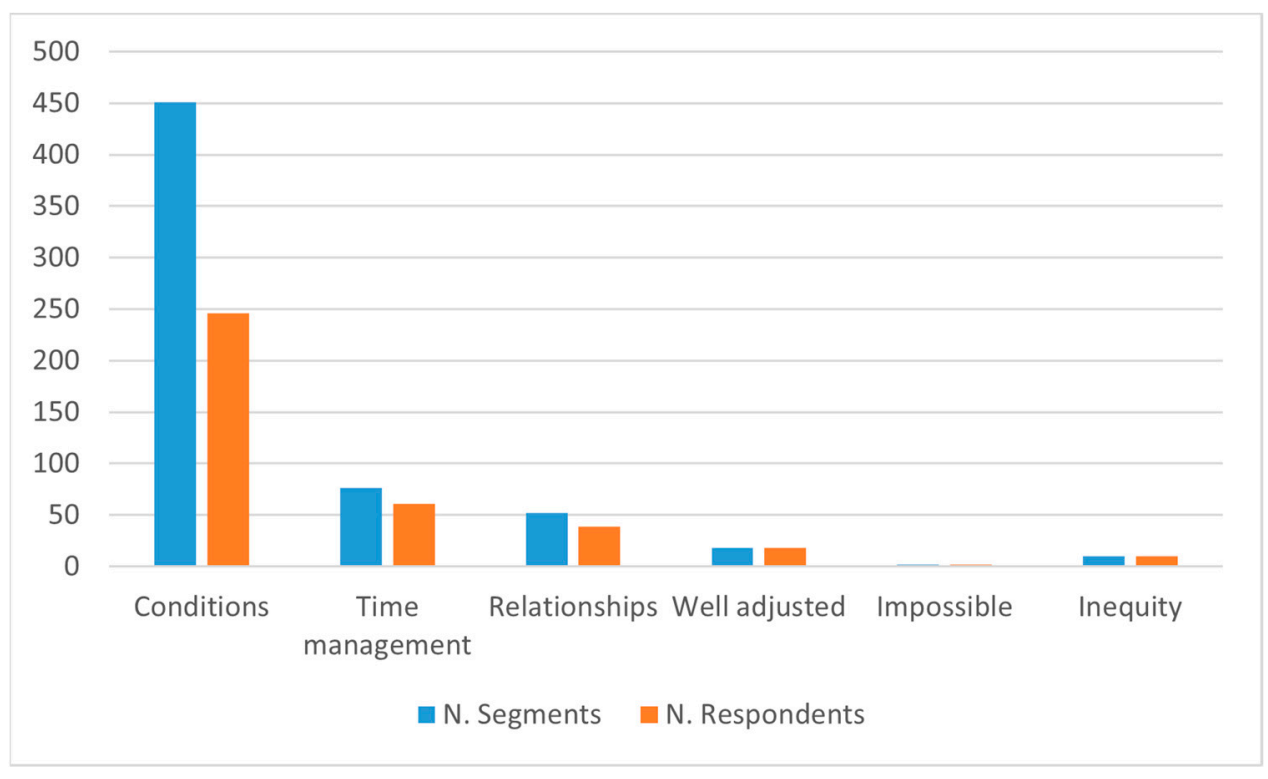

Figure 6. Students' constraints: an overview of responses and respondents to each category.

\subsubsection{Conditions}

Conditions were further divided into (a) personal conditions-digital competence (73), autonomy (42), organization (37), involvement/ motivation (35), understanding (12), concentration (9), behavior (2), and information management (1); (b) contextual and material conditions - equipment (93), internet (37), coordination (4), economic (1), and environment (1); and (c) family-related conditions (79) (Figure 7). 


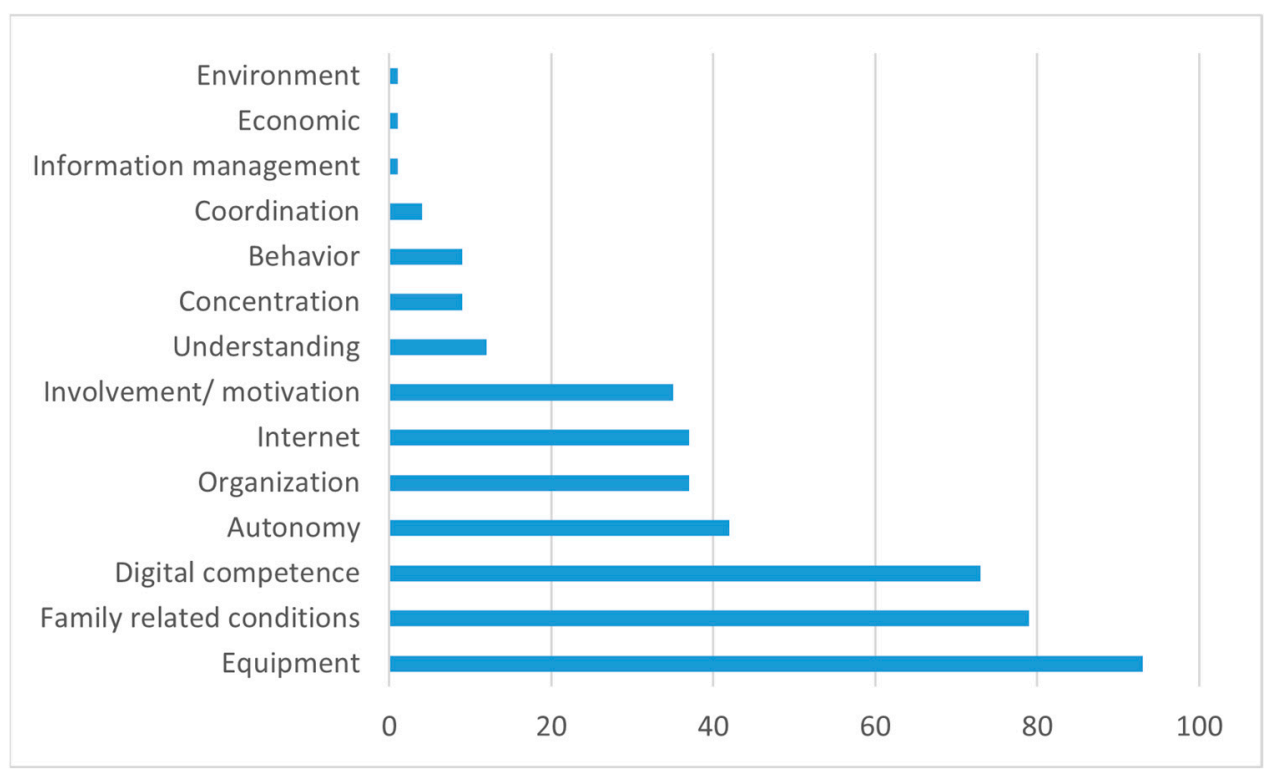

Figure 7. Students' constraints: frequency of references to subcategories under the category of conditions.

Within personal conditions, students' digital competences were highlighted as the most significant constraint to their success in adapting to this rapid transition. For instance, r. 83 stated "it turns out students don't master technologies as well as we thought", or, in the words of r. 152, "Their lack of ICT knowledge. Students have knowledge for gaming, but not for study and work".

Additionally, students' transversal competencies in autonomy, organization, concentration, or even their ability to understand what was asked of them were frequently cited.

Among contextual and material conditions, besides references to the insufficiency or inadequacy of the equipment and internet some of the students have (or do not have) access to, other contextual factors were mentioned, including the lack of coordination among teachers or at higher levels, which impacts students indirectly, economic factors, and the lack of access to a good environment for learning.

Lastly, family-related issues were also very frequently reported, mainly concerning the lack of involvement of some parents, but occasionally an excessive involvement. We present an example of this latter situation:

"Some work is clearly not done by the students. ( . . ) It is good to have family support, but guidance does not mean doing the student's job for them" (r. 48).

Other family-related issues include the management of family and learning responsibilities, the difficulties posed by families' lower digital competence or the fact that equipment must be shared among siblings and with parents who are also working from home.

Students' access to technology and the internet [41], physical conditions for learning [41,45], and parents' availability, involvement, and ability to help their children [41,42,45], were also pointed out by other studies and affect equity of students, which is a major concern with ERTL [22,30,55].

\subsubsection{Time Management}

Time management was also portrayed as an important issue for students, similarlyalthough not as intensely - to what was expressed concerning teachers. In this category, we include the subcategories time (43), overload (23), and synchronous classes (10).

Managing their time, in general, was seen as one of the students' difficulties, in some cases justified by the perception of an overload of tasks being required of them. This overload relates to the process being inefficiently coordinated; for example, r. 98 states that the excess of activities proposed daily happens by "school imposition", another respondent 
states that demands are uncoordinated (among teachers) (r. 68). On another note, r. 313 refers to the "intention some teachers have of trying to transpose a face-to-face class to an online class". Synchronous classes were included in this category for this very reason: they make the management of both time and access to equipment (when sharing with family members) particularly challenging.

Although this specific concern was not found in other studies concerning teachers' perspectives, a vital concern about students' wellbeing was reported in multiple studies $[22,41,42]$.

\subsubsection{Relationships}

Within this category, other subcategories were considered, namely peers (20), contact with the teacher (15), missing the school (11), shyness (4), and teamwork (2).

The lack of social contact, particularly among the students, was stressed as a limitation, for instance, "lack of in presence contact (missing their teammates and the school environment)" (r. 118).

The lack of a face-to-face contact with the teacher was also mentioned, "the need to expose their difficulties with the teacher, face to face" (r. 99) or "there are many students who need to feed their learning with affection, who complete the tasks because they care, they want to please the adult" (r. 285).

The school environment itself is also mentioned, such as "they miss the classroom space and are tired of being at home" (r. 60).

The fact that some students may feel shy about exposing their work online is mentioned by some respondents, as is the absence of teamwork. These aspects align with the holistic teaching responses category in the study of MacDonald and Hill [42] and with pedagogical challenges described by Ferri and collaborators [41], or with some of the concerns expressed by teachers in Hamilton and collaborators' study [22]. Keeping the relations between students and teachers is also one of the proposals of Reimers and Schleicher [19].

\subsubsection{Well Adjusted/Impossible}

Eighteen teachers considered their students had, for the most part, or entirely, adjusted well to this unexpected situation (more than those who considered themselves, as teachers, as having had no difficulties in the process). We exemplify with the words of r. 94: "They adapted better than me. They are building their portfolios with a lot of motivation and commitment". One of the teachers in MacDonald and Hill's study [42] also pointed out that some students seemed to improve their attendance during ERTL.

Although a small minority, two teachers (both preschool teachers) stressed it is impossible to teach preschool at a distance. As we mentioned before, childhood education, due to its connection to everyday and real-life experience, as well as children's greater dependence on parents, faces particular challenges when moved online [45].

\subsubsection{Inequity}

Concerns about equity have permeated the responses to this question, as well as to the previous one, emerging as one of the pressing matters this pandemic has brought to light. For the previous question, 29 teachers had expressed concerns about equity, and 10 expressed the same concern in response to the students' limitations.

Inequality in access to technological means and the internet, inequality in the degree of support from families, and social and economic asymmetries may well have been preexisting conditions. However, they were increased by the pandemic (increasing social and economic inequality) and learning from home, as has previously been pointed out $[22,30,38,42,45]$. Concerns about the fairness of evaluation also punctuated the speech of some of the respondents, as was the case with some teachers in a previous study [22]. These remain some of the most sensitive issues in ERTL. 
These concerns are aligned with those described as characteristic of ERTL phase $2[14,35]$

\subsection{Potential and Positive Aspects}

Two hundred seventy teachers answered the open question, "Please identify the main potentialities and positive aspects you have identified in this process".

Their answers were categorized into four main categories-competence development (185 mentions, by 139 teachers), features and potentials (123 mentions by 103 teachers), valuing ( 62 references by 47 respondents), and learning ( 43 segments by 35 respondents) —each of which was specified by subcategories, and four complementary categories-nonexistent (18), negative aspects (2), convenience (7), and health (2) (Figure 8).

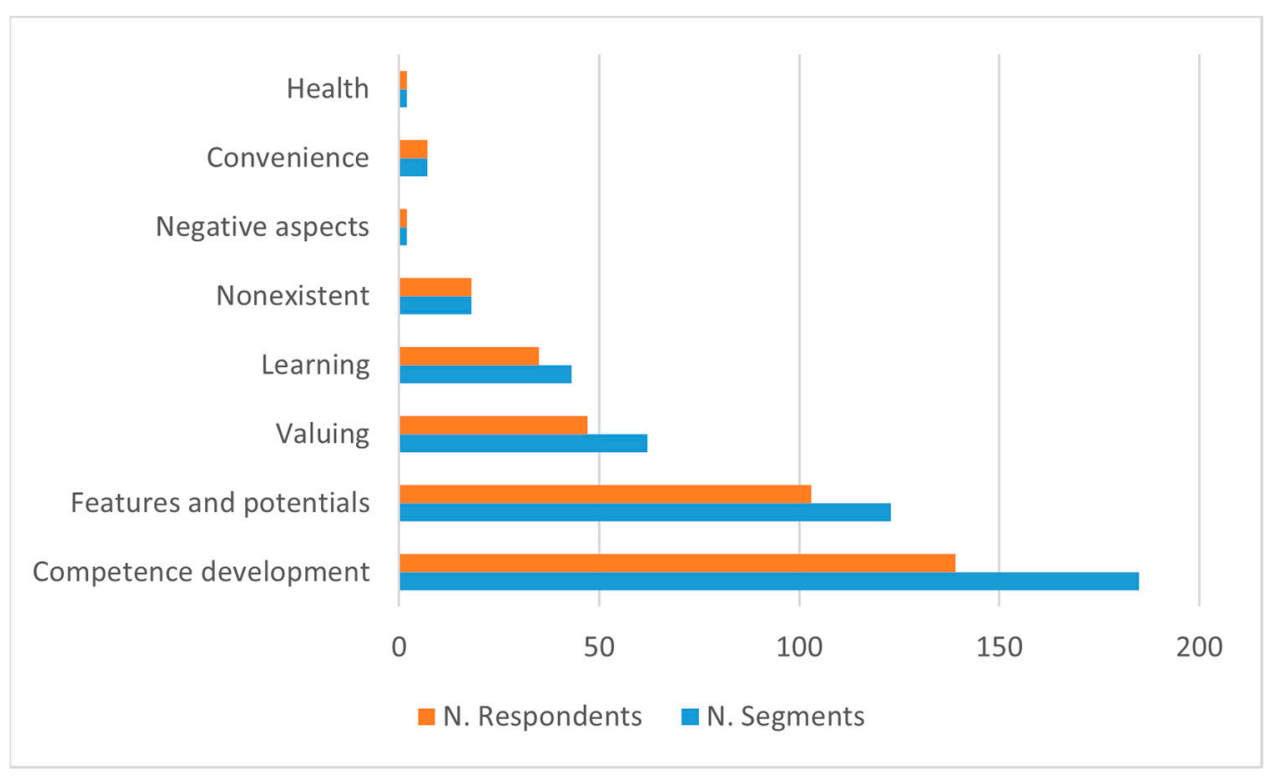

Figure 8. Potential and positive aspects: an overview of responses and respondents to each subcategory.

\subsubsection{Competence Development}

The respondents identified a variety of competences as being developed through this experience, both in themselves and in their students, and marginally affecting the students' families, namely, digital competences (63), autonomy (55), motivation (21), responsibility (21), adaptation (11), organization (11), creativity (5), and concentration (3).

For instance, about digital competences, r. 33 remarks: "The fact that many people were forced to work with technology as a work tool increases their digital literacy and potentiates their competences". Touching on autonomy and responsibility: "Autonomy and responsibility are naturally stimulated by this model" (r. 68). Regarding motivation: "the commitment the overwhelming majority of my students show in fulfilling the tasks I propose them" (r. 292). About creativity, mentioned less frequently: "I verify most of my students do the practical tasks much faster and with more creativity, as if they had more tranquility to think, to imagine, ..." (r. 151).

Other studies also showed the experience of ERTL to be a period of growth and development for both students and teachers, including at the level of competence development $[42,44]$.

It is worth noting that there is a very close correspondence between the competences that were found lacking in students (and in some cases in teachers), hindering their adaptation to this process, and those found to have been developed through this experience.

\subsubsection{Features and Potential}

Under this category, we organized ideas referring to features of this very experience which are seen as having inherent potential, including being an opportunity to change 
teaching and learning (39), focusing on the student/student involvement (35), collaborative work (13), students' behavior (12), opportunity to change evaluation (12), online meetings (8), and modality adequate for specific audiences (3).

Seeing this experience as an opportunity to change teaching and learning, with potential impacts on the post-pandemic future, was a relevant lesson extracted by some of the respondents. For instance:

"Proving we can build knowledge networks and exchange ideas outside the classroom, taking a digital leap into a new future" (r. 307).

"Technological solutions we now use more efficiently, and we will probably not stop using" (r. 261).

Student-centered learning, the opportunity to adapt teaching to each individual student, and students' active participation in learning were also mentioned as features of this way of teaching:

"The main [advantage]: the student as a subject of his own learning" (r. 139).

"Each student solves the proposed tasks in their own rhythm and presents it, unlike in face-to-face classes where many do nothing" (r. 77).

Teamwork and sharing were mentioned, not being limited to the students but sometimes explicitly encompassing the teachers' work.

The references to students' behavior, although presented as a positive outcome of the experience, were sometimes ambiguous, seeming to imply the idea that even if students were still misbehaving, they were muted and therefore "silent". In other instances, teachers referred to an actual improvement in behavior. For instance:

"We normally don't have the tiresome part of telling students to be silent, or to pay attention, or to stop using their phone. However, that happens because we cannot control the student in their home" (r. 209).

"No more truancy and students' misbehavior during the class" (r. 264).

Changes in evaluation, mainly concerning diversification of instruments and the shift towards a more formative perspective, were also mentioned, such as by r. 3, "evidence of individual student's work which allows us to provide differentiated and high-quality feedback".

Concerning meetings, there were mentions of the "perception meetings can be held online (finally!)" (r. 289).

A small number of respondents highlighted that distance learning (or blended learning) is something that responds to the needs of specific publics (working students-r. 37, students with long-term illness—r. 100, and secondary education students_r. 193) and may continue after the pandemic as a response to their needs.

Some of the potential aspects pointed out by the students in our study included promoting changes to teaching and learning, allowing students to be more active in the process of learning, and changing teacher-student relations [11], structurally impacting evaluation, feedback, and education as a whole, and mirroring the prospective views expressed by several scholars $[6,9,27,31]$. We note, however, that other teachers found other entirely operational, positive, practical aspects in ERTL, and some were unable to see any potential in the experience. These findings highlight the diversity in how teachers lived and experienced this process, with likely impacts on the quality of education provided to their students.

\subsubsection{Valuing}

In this category, we grouped several subcategories pertaining to learning to value different aspects considering this experience: parental involvement (31), family relations (6), online learning (6), the teacher (6), the school (5), human contact (4), and face-to-face education (4). A minority of these contain a negative nuance (such as valuing face-toface education in contrast to a negative ERL experience). However, most point to a 
reorganization of priorities and learning more about each other (school and family) due to this process.

For instance, concerning parental involvement, "families learning together" (r. 54), or "on the part of the parents-promoting a greater contact with the school and deeper involvement in the whole process".

Concerning family relations and valuing the teacher, "parents having more time for their children. The work done by preschool teachers is now more recognized" (r. 40).

Family involvement was also mentioned by MacDonald and Hill [42], although not always in a positive light.

\subsubsection{Learning}

This category refers to, on the one hand, making learning possible, despite the dire circumstances, such as what is expressed in the subcategories staying in touch with students (15), making learning go on (10), allowing synchronous classes (3), or access to information (2), in a logic that seems to want to maintain the status quo. Less frequently, respondents go further to consider the possibilities for improvement opened by this experience, such as in the categories complement to face-to-face learning (8) and new/better learning (4). These aspects closely relate to Reimers and Schleicher's [19] appeals to ensure access to education is maintained.

\subsubsection{Nonexistent/Negative Remarks}

Eighteen respondents considered there were no positive outcomes to this experience. Two others, despite being asked to indicate positives, still needed to point out a caveatonce concerning equity and once concerning the overburden that the situation entails.

Looking closer at the 18 teachers who stated they could not find anything positive, we sought to find any possible trends that could be drawn from their personal and professional characteristics. The group did not show relevant trends in terms of age or gender. However, teachers of younger children were overrepresented (two preschool teachers, six 1st cycle of basic education teachers (CBE), one teacher who taught 1st and 2nd CBE and three 2nd CBE teachers, in a total of 14 teachers of children aged 1 through 12, compared to no 3rd CBE teachers and four secondary education teachers). This may constitute a relevant indicator, which may be further investigated.

\subsubsection{Convenience and Health}

A relatively small number of teachers indicated positive outcomes not directly related to education, including convenience (no traffic, for instance) or the fact that working from home helped protect their health in the context of the pandemic.

\section{Conclusions}

The transition to ERTL due to schools' closure in the spring of 2020 presented the education sector with an unprecedented and complex challenge. Although educational research has been able to identify common traits in this global phenomenon, the impact of the pandemic differed from country to country, depending on diverse factors, such as government policy, social and economic conditions, and cultural background.

In this article, we present the findings from a Portuguese qualitative study into teachers' perspectives on ERTL, focusing on their initial responses to the first lockdown. It focuses on the perspectives of 305 Portuguese teachers from preschool (students aged 3-6), 1st, 2nd, and 3rd cycles of basic education (CBE) (students aged 6-14), and secondary education (students aged 14-18). We have looked at their perceived difficulties with the transition to ERTL as well as their views on the constraints faced by their students, but also the potential and positive aspects they recognized in the process.

From the findings, we may conclude that Portuguese teachers perceived the transition to ERTL with concern, although a large majority also see this phenomenon as an opportunity for positive transformation of educational practices and of their own and their 
students' competences. Only a small number shared an entirely negative experience. The main concerns expressed relate to work overload, conditions for ERTL-among which access to technological means and the internet, as well as the necessary digital competences are highlighted-and time management. This is aligned with a previous international study [44], as the perception of work overload correlated with teachers' lack of digital competence has been identified in studies worldwide [23]. The same applies to how teachers perceive the increased workload as affecting their private and family life [17,42].

Portuguese teachers highlight the lack of appropriate or clear guidance and coordination from the Portuguese government or their schools' leadership throughout the crisis. This is particularly noted concerning critical components of the pedagogical process, such as evaluation, assessment, and feedback. Concerns with cheating and unethical student practices were shared by some, and this has affected their trust in the quality of ERTL. During the COVID-19 crisis, the government followed a mostly decentralized approach, which allowed more autonomy in adjusting their practices to their specific contexts without having to rely on generic and in some cases unproven guidelines, and allowing schools to develop bottom-up projects. However, this relative lack of guidance seems to have led to difficulties in coordinating the educational response, at least in some schools-the discrepancies at this level may result in additional inequity of students [26].

The major difficulty perceived by Portuguese teachers, however, relates to poor infrastructure (quality and availability of the internet, hardware, software) and the lack of digital competences. The first is seen as affecting access and equity in education, thus hindering its social role [26].

Social cohesion mitigates the adverse effects of isolation, depression, and similar causes of distress [3,4]. The findings show that Portuguese teachers are aware of this, as they show concern for both equity and relationships, when they reflect on the students' limitations.

Teachers are aware of the importance of online didactics and the quality of learning design and that they consider their relative lack of digital competences to have been a hindrance to this process. Likewise, they also acknowledge the need for more and better training for technologically enhanced teaching and learning [26]. Nevertheless, most still perceive teachers' digital competences as being technological abilities. This suggests the need not only to improve digital literacy in general but to re-design teacher training in Portugal, giving digital competence development a focal role.

Another key finding of this study concerns teachers' perceptions of how students experienced the transition to ERTL. Teachers frequently had difficulty separating their personal concerns from the ones of their students, which is interesting and significant in terms of how powerful and intense this experience was for educational communities. The students' difficulties, as perceived by the teachers, include students' conditions for ERTL, such as unequal access to computers and the internet at home, their lack of digital competences, and their excessive workload and burnout. These concerns point to an underlying issue: that of inequality. It has not often been highlighted in the literature how the COVID-19 crisis has contributed to changing teachers' perception of students' digital literacy [16]. Teachers are beginning to realize the difference between technological savviness and digital competence. As such, our data show that many teachers realize their students require training for digital and online learning.

Portuguese teachers also expressed their perception that students suffered from a lack of participation and motivation in the transition to ERTL. From their comments, we can hypothesize that this may result from poor learning design. There are also observations regarding the importance of a positive family environment and the active role of parents. This follows what has been identified in the international literature. Strict enforcement of social distance policies, especially at the time of the lockdowns, has blurred the borders between schooling and home schooling. Following the groundbreaking publication of the Plowden Report [56], parents' involvement and support has been considered a cornerstone of good distance learning practice for K12. 
In addition, teachers also point out concerns with isolation and student autonomy. Given that many of the respondents were teachers from preschool and 1st CBE, in which students are less autonomous and still require much individual support, ERTL was not perceived as very efficient. Both the Portuguese authorities and institutions lacked experience in distance and online learning with these early age groups, and this was not helpful to support teachers adjusting to ERTL.

One important limitation of the present paper is the fact that it presents only one perspective on the process of ERTL, as it focuses on teachers' concerns and experiences. In the analysis presented in this paper, students' constraints are considered solely from their teachers' perspectives, which is limited as teachers may not be fully aware of their students' experiences.

The data gathering was also restricted to an interesting and rich, but specific, time frame.

To address these limitations, future research should consider and compare different perspectives on the ERTL phenomenon, as well as follow its development and implications as education moves towards a "new normal". The importance of teachers' and students' digital competences highlighted in the present study has important implications for practice, as well as for research. The issues of equity - in access and quality of education-also merits further investigation and is a priority concern for educational practice.

The response to the COVID-19 pandemic has accelerated the digital transformation of schools in Portugal and worldwide [26,44,57]. The recent EU Digital Education Action Plan (2021-2027) (https: / / ec.europa.eu/education/education-in-the-eu/digital-educationaction-plan_en accessed 18 June 2021) embodies this phenomenon. This movement represents a new and more complex phase that builds up from the experience of ERTL. In this new context of mainstreaming online and hybrid education, institutions, teachers, and all other stakeholders are called to embrace a more profound transformation. Our future research is intended to follow this movement, collecting evidence of how teachers will continue to perceive this phenomenon.

Author Contributions: Conceptualization, F.S., L.A. and A.T.; methodology, F.S.; validation, F.S.; formal analysis, F.S.; investigation, F.S.: data curation, F.S.; writing-original draft preparation, F.S., L.A., M.A. and A.T.; writing-review and editing, F.S., L.A., M.A. and A.T.; visualization, F.S.; supervision, F.S.; project administration, F.S. All authors have read and agreed to the published version of the manuscript.

Funding: This research was financed by national funds through FCT—Fundação Para a Ciência e a Tecnologia, I.P., in the projects UIDB/04372/2020 and UIDP/04372/2020.

Institutional Review Board Statement: The study was conducted according to the guidelines of the Declaration of Helsinki, and approved by the Ethics Committee of the LE@D (Laboratório de Educação e Ensino a Distância, Universidade Aberta, Portugal) (29 April 2020).

Informed Consent Statement: Informed consent was obtained from all subjects involved in the study.

Data Availability Statement: The data are not publicly available due to the confidential information involved, as per the confidentiality agreement established with the participants.

Conflicts of Interest: The authors declare no conflict of interest.

\section{References}

1. David, B.E.; Kumar, S. Psychological Health Problems during the Lockdown: A Survey of Indian Population in COVID-19 Pandemic. Data Brief 2000, 33, 106566. [CrossRef]

2. Davis, C.R.; Grooms, J.; Ortega, A.; Rubalcaba, J.A.A.; Vargas, E. Distance Learning and Parental Mental Health During COVID-19. Educ. Res. 2021, 50, 61-64. [CrossRef]

3. Kim, J. The Role of Social Cohesion in Addressing the Impact of COVID-19 on Mental Health within Marginalized Communities. Local Dev. Soc. 2020, 1, 205-216. [CrossRef]

4. Miao, J.; Zeng, D.; Shi, Z. Can Neighborhoods Protect Residents from Mental Distress during the COVID-19 Pandemic? Evidence from Wuhan. Chin. Sociol. Rev. 2021, 53, 1-26. [CrossRef]

5. United Nations Education during COVID-19 and Beyond; 2020. Available online: https:/ /www.un.org/development/desa/dspd/ wp-content/uploads/sites/22/2020/08/sg_policy_brief_covid-19_and_education_august_2020.pdf (accessed on 9 June 2021). 
6. Adedoyin, O.B.; Soykan, E. Covid-19 Pandemic and Online Learning: The Challenges and Opportunities. Interact. Learn. Environ. 2020, 1-13. [CrossRef]

7. Zierer, K. Effects of Pandemic-Related School Closures on Pupils' Performance and Learning in Selected Countries: A Rapid Review. Educ. Sci. 2021, 11, 252. [CrossRef]

8. UNESCO Education: From Disruption to Recovery. Available online: https://en.unesco.org/covid19/educationresponse (accessed on 24 May 2021).

9. Burns, J.P.; Cruz, C. The Promise of Curriculum in the Post-Covid World: Eclecticism, Deliberation, and a Return to the Practical and the Prophetic. Prospects 2021. [CrossRef]

10. European Centre for Disease Prevention and Control COVID-19 in Children and the Role of Schoolsettings in COVID-19 Transmission; ECDPC: Stockholm, Sweden, 2020.

11. Goodson, I.F.; Schostak, J.F. Curriculum and Coronavirus: New Approaches to Curriculum in the Age of Uncertainty. Prospects 2021. [CrossRef]

12. Seabra, F.; Aires, L.; Teixeira, A. Transição Para o Ensino Remoto de Emergência No Ensino Superior Em Portugal—Um Estudo Exploratório. Dialogia 2020, 316-334. [CrossRef]

13. Hodges, C.; Moore, S.; Lockee, B.; Trust, T.; Bond, A. The Difference Between Emergency Remote Teaching and Online Learning. Available online: https:/ / bit.ly/3hx5amz (accessed on 21 May 2021).

14. Barbour, M.K.; Hodges, C.B.; Trust, T.; LaBonte, R.; Moore, S.; Bond, A.; Kelly, K.; Lockee, B.; Hill, P. Understanding Pandemic Pedagogy: Differences between Emergency Remote, Remote, and Online Teaching; A Special Report of the State of the Nation: K-12 E-Learning in Canada Project; Canadian eLearning Network: Halfmoon Bay, BC, Canada, 2020. [CrossRef]

15. Czerniewicz, L.; Agherdien, N.; Badenhorst, J.; Belluigi, D.; Chambers, T.; Chili, M.; De Villiers, M.; Felix, A.; Gachago, D.; Gokhale, C.; et al. A Wake-Up Call: Equity, Inequality and Covid-19 Emergency Remote Teaching and Learning. Postdigital Sci. Educ. 2020, 2, 946-967. [CrossRef]

16. Gewerc, A.; Persico, D.; Rodes-Paragarino, V. Guest Editorial: Challenges to the Educational Field: Digital Competence the Emperor Has No Clothes: The COVID-19 Emergency and the Need for Digital Competence. IEEE Rev. Iberoam. Tecnol. Aprendiz. 2020, 15, 372-380. [CrossRef]

17. Bozkurt, A.; Sharma, R.C. Emergency Remote Teaching in a Time of Global Crisis Due to CoronaVirus Pandemic. Asian J. Distance Educ. 2020, 15, i. [CrossRef]

18. Baggaley, J. Educational Distancing. Distance Educ. 2020, 41. [CrossRef]

19. Reimers, F.M.; Schleicher, A. A Framework to Guide an Education Response to the COVID-19 Pandemic of 2020 I Unesco IIEP Learning Portal; UNESCO: Paris, France, 2020.

20. Azubuike, O.B.; Adegboye, O.; Quadri, H. Who Gets to Learn in a Pandemic? Exploring the Digital Divide in Remote Learning during the COVID-19 Pandemic in Nigeria. Int. J. Educ. Res. Open 2020, 100022. [CrossRef]

21. Osman Abdelmola, A.; Makeen, A.; Makki Hanafi, H.; Ageeli, E. E-Learning during COVID-19 Pandemic, Faculty Perceptions, Challenges, and Recommendations. MedEdPublish 2021, 10. [CrossRef]

22. Hamilton, L.S.; Kaufman, J.H.; Diliberti, M. Teaching and Leading through a Pandemic: Key Findings from the American Educator Panels Spring 2020 COVID-19 Surveys; RAND Corporation: Santa Monica, CA, USA, 2020.

23. Portillo, J.; Garay, U.; Tejada, E.; Bilbao, N. Self-Perception of the Digital Competence of Educators during the Covid-19 Pandemic: A Cross-Analysis of Different Educational Stages. Sustainability 2020, 12, 10128. [CrossRef]

24. Daniel, J. Education and the COVID-19 Pandemic. Prospects 2020, 49, 91-96. [CrossRef]

25. Toquero, C.M. Emergency Remote Education Experiment amid COVID-19 Pandemic. IJERI Int. J. Educ. Res. Innov. 2020, $162-176$. [CrossRef]

26. Pacheco, J.A.; Morgado, J.C.; Sousa, J.; Maia, I.B. Educação Básica e Pandemia. Um Estudo Sobre as Perceções Dos Professores Na Realidade Portuguesa. Rev. Iberoam. Educ. 2021, 86. [CrossRef]

27. Pacheco, J.A. The "New Normal" in Education. Prospects 2020. [CrossRef]

28. Morgado, J.C.; Sousa, J.; Pacheco, J.A. Educational Transformations in Pandemic Times: From Social Confinement to Curriculum Isolation. Prax. Educ. 2020, 15. [CrossRef]

29. Vieira, M.D.F.; da Silva, C.M.S. A Educação No Contexto Da Pandemia de COVID-19: Uma Revisão Sistemática de Literatura. Rev. Bras. Inf. Educ. 2020, 28, 1013-1031. [CrossRef]

30. Dias-Trindade, S.; Correia, J.D.; Henriques, S. Ensino Remoto Emergencial Na Educação Básica Brasileira e Portuguesa: A Perspectiva Dos Docentes. Rev. Tempos Espaços Educ. 2020, 13, 1-23. [CrossRef]

31. Azevedo, J. COVID e educação: Da emergência às oportunidades. In Ensinar e Aprender em Tempo de COVID 19: Entre o caos e a Redenção; Matias Alves, J., Cabral, I., Eds.; Faculdade de Educação e Psicologia da Universidade Católica Portuguesa: Porto, Portugal, 2020; pp. 83-86. ISBN 9789895436460.

32. Carrillo, C.; Flores, M.A. COVID-19 and Teacher Education: A Literature Review of Online Teaching and Learning Practices. Eur. J. Teach. Educ. 2020, 43, 466-487. [CrossRef]

33. Assunção Flores, M.; Gago, M. Teacher Education in Times of COVID-19 Pandemic in Portugal: National, Institutional and Pedagogical Responses. J. Educ. Teach. 2020, 46, 507-516. [CrossRef]

34. Conselho Nacional de Educação. Educação Em Tempo de Pandemia: Problemas, Respostas e Desafios Das Escolas; CNE: Lisboa, Portugal, 2021. 
35. Hill, P. Revised Outlook for Higher Ed's Online Response to COVID-19. Available online: https:/ / bit.ly/2SYF55F (accessed on 24 May 2021).

36. General Directorate of Education Roteiro-8 Princípios Orientadores Para a Implementação Do Ensino a Distância (E@D) Nas Escolas. Available online: https://www.dge.mec.pt/noticias/roteiro-8-principios-orientadores-para-implementacao-do-ensinodistancia-ed-nas-escolas (accessed on 26 May 2021).

37. General Directorare of Education Formação Para a Docência Digital e Em Rede. Available online: https://www.dge.mec.pt/ noticias / formacao-para-docencia-digital-e-em-rede (accessed on 26 May 2021).

38. Aguliera, E.; Nightengale-Lee, B. Emergency Remote Teaching across Urban and Rural Contexts: Perspectives on Educational Equity Emergency Remote Teaching 471. Inf. Learn. Sci. 2020, 121, 471-478. [CrossRef]

39. Khlaif, Z.N.; Salha, S.; Affouneh, S.; Rashed, H.; ElKimishy, L.A. The Covid-19 Epidemic: Teachers' Responses to School Closure in Developing Countries. Technol. Pedagog. Educ. 2020. [CrossRef]

40. Sá, M.J.; Serpa, S. The Global Crisis Brought about by SARS-CoV-2 and Its Impacts on Education: An Overview of the Portuguese Panorama-Ft. Sci. Insights Educ. Front. 2020, 5, 525-530. [CrossRef]

41. Ferri, F.; Grifoni, P.; Guzzo, T. Online Learning and Emergency Remote Teaching: Opportunities and Challenges in Emergency Situations. Societies 2020, 10, 86. [CrossRef]

42. MacDonald, M.; Hill, C. The Educational Impact of the Covid-19 Rapid Response on Teachers, Students, and Families: Insights from British Columbia, Canada. Prospects 2021. [CrossRef]

43. Sokal, L.; Trudel, L.E.; Babb, J. Canadian Teachers' Attitudes toward Change, Efficacy, and Burnout during the COVID-19 Pandemic. Int. J. Educ. Res. Open 2020, 1, 100016. [CrossRef]

44. Carretero Gomez, S.; Napierala, J.; Bessios, A.; Mägi, E.; Pugacewicz, A.; Ranieri, M.; Triquet, K.; Lombaerts, K.; Robledo Bottcher, N.; Montanari, M.; et al. What Did We Learn from Schooling Practices during the COVID-19 Lockdown, EUR 30559 EN; European Commission Joint Research Centre (JRC): Luxembourg, 2021.

45. Spiteri, J. Quality Early Childhood Education for All and the Covid-19 Crisis: A Viewpoint. Prospects 2021. [CrossRef]

46. Schuck, R.K.; Lambert, R. “Am I Doing Enough?" Special Educators' Experiences with Emergency Remote Teaching in Spring 2020. Educ. Sci. 2020, 10, 320. [CrossRef]

47. Aktan, S. Waking up to the Dawn of a New Era: Reconceptualization of Curriculum Post Covid-19. Prospects 2021. [CrossRef]

48. Anonymous. AERA Code of Ethics American Educational Research Association. Educ. Res. 2011, 40, 145-156. [CrossRef]

49. Kuckartz, U.; Rädiker, S. Analyzing Qualitative Data with MAXQDA Text, Audio, and Video; Springer: Cham, Switzerland, 2019; ISBN 978-3-030-15671-8.

50. Mayring, P. Qualitative Content Analysis Theoretical Foundation, Basic Procedures and Software Solution; SSOAR: Klagenfurt, Austria, 2014.

51. Creswell, J.W. Qualitative Inquiry and Research Design: Choosing among Five Approaches, 3rd ed.; SAGE: Los Angeles, CA, USA, 2013; ISBN 978-1-4129-9530-6.

52. Gizzi, M.C.; Rädiker, S. The Practice of Qualitative Data Analysis, 1st ed.; MAXQDA Press: Berlin/Heidelberg, Germany, 2021; ISBN 978-3-948768-10-2.

53. Rädiker, S.; Kuckartz, U. Step by Step Focused Analysis of Qualitative Interviews with MAXQDA, 1st ed.; MAXQDA Press: Berlin/Heidelberg, Germany, 2020.

54. UNESCO. Supporting Teachers and Education Personnel during Times of Crisis; UNESCO Digital Library: Paris, France, 2020; Available online: https:/ / unesdoc.unesco.org/ark:/48223/pf0000373338 (accessed on 9 June 2021).

55. Aguilera-Hermida, A.P. College Students' Use and Acceptance of Emergency Online Learning Due to COVID-19. Int. J. Educ. Res. Open 2020, 1, 100011. [CrossRef]

56. Blackstone, T. The Plowden Report. Br. J. Sociol. 1967, 18. [CrossRef]

57. Iivari, N.; Sharma, S.; Ventä-Olkkonen, L. Digital Transformation of Everyday Life-How COVID-19 Pandemic Transformed the Basic Education of the Young Generation and Why Information Management Research Should Care? Int. J. Inf. Manag. 2020, 55. [CrossRef] 